\title{
The Effect of Light of Different Intensities, Reduced Selectively and Non-selectively, upon the Rate of Growth of Nitzschia closterium.
}

By

\section{F. A. Stanbury, M.Sc.}

With 7 Figures in the Text.

\section{INTRODUCTION.}

THE effect of light upon plant growth is a problem which has attracted many workers since the discovery of Priestly, in 1771, that a plant could purify fixed air, carbon dioxide, which was followed by the supplementary work of Ingen-Housz and Senebier, who showed that the phenomenon was associated with the nourishment of the plant, and took place only in sunlight and through the agency of the green portions of the plant.

Senebier, 1782, was perhaps the first to attempt to show the effect of the different parts of the spectrum on the process, and found that red light was almost as active as ordinary light in the process of photosynthesis whilst the blue was almost inactive. Draper and Daubeny, 1844, concluded that after white light, the red-yellow portion possessed the highest efficiency, and this was supported by Sachs in 1868. Englemann, Timiriazeff and Wolkaff, however, found that whilst the activity in the red was high, there was an important secondary maximum of efficiency in the blue, and these results have been subject to great controversy amongst later workers.

It must be borne in mind that the physics of the light used by the early investigators was not thoroughly understood, and one of the greatest criticisms brought against these workers is that the blue light used by them contained parasitic rays of long wave lengths, viz. in the red region. Dangeard (1927) asserts that in light of feeble intensity, these parasitic rays are practically inactive, but in light of greater intensity they play a highly important role, and are the cause of the secondary maximum observed by many workers. Richter (1902) using coloured screens, concluded that the rate of photosynthesis was proportional to the amount of energy absorbed, independent of the part of the spectrum and the wave length of the ray, and Kniep and Minder (1909) determined that the 
action of the red and the blue was almost similar when the energy in those regions was the same.

Klugh (1925) sought to determine whether photosynthesis was a wave length phenomenon, or dependent upon the total light intensity. To do this he grew unicellular algæ, in light which he regarded to be of the same intensity but of different wave lengths, and took the rate of reproduction as criteria for efficiency of the wave lengths concerned in photosynthesis, for although the method was indirect it was assumed that, fundamentally, the rate of reproduction in chlorophyllous organisms is dependent on the ability to manufacture food. From a single series of experiments lasting from August 16th-September 10th he concluded that photosynthesis is a wave length phenomenon, red light being highly efficient, blue much less so, and green inefficient, but Klugh himself in his concluding remarks says "that it is dangerous to draw conclusions from a single series of experiments."

Using somewhat similar methods to those of Klugh, results are now presented in this paper, which would show that photosynthesis, as indicated by the rate of growth of marine diatoms, is a function of the amount of energy transmitted independent of the wave length between which the energy so transmitted lies.

\section{Plant material used.}

Persistent cultures of the marine diatom Nitzschia closterium, grown in "Miquel sea water," were used for the plant growths to be studied, a persistent culture, as defined by Allen and Nelson (1910), being one in which only one species of diatom was present, although there might be bacteria.

It is of interest to mention here, that marine diatoms exhibit wellmarked periodicity in the sea, the diatom outburst being at its height between early March and late April. The cause of these outbursts is not fully understood.

Marshall and Orr (1928) concluded that the length of day was a factor of the greatest importance, whilst Atkins, Herdman, Scott and Dakin correlated the early spring sunshine with the diatom outburst. Atkins (1928) also found that " a study of the phosphate change affords a measure, in an inverse ratio, of the production of the algal crop, and indicates from year to year the variations that occur in its seasonal waxing and waning."

From results obtained using the marine diatom Nitzschia closterium it would appear that the total light intensity is a factor which has a profound effect upon growth. 


\section{Method.}

It was desired to determine the effect of light of selected wave lengths and of daylight reduced in intensity non-selectively, upon the rate of growth of Nitzschia closterium, and this was done by growing cultures of Nitzschia under a series of selective and non-selective filters.

Equal volumes of " Miquel sea water," contained in sterilized crucibles of white porcelain of 10 cubic centimetres capacity and 3.5 centimetres

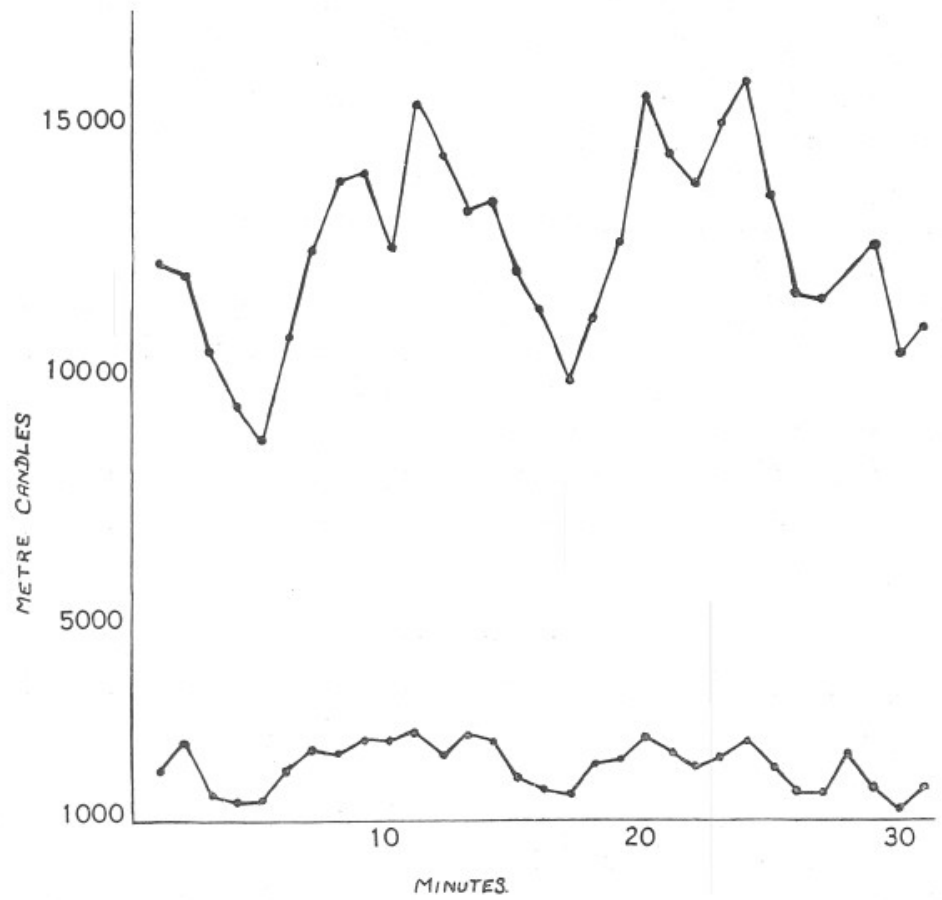

FIG. 1.-Curves showing the variations in illumination for the north window, lower curve, where the cultures were set, and for an open site on the laboratory wall, upper curve, determined simultaneously for a period of 30 minutes. The numbers along the ordinates represent the illumination in metre candles. Those along the abscissæ the time in minutes.

diameter, were inoculated with similar drops of a persistent culture solution, which contained known numbers of diatoms per unit of volume.

The number of diatoms in any culture was determined with the aid of a hœmacytometer, the millimetre square being ruled in Thoma pattern. The culture to be examined was first thoroughly mixed by means of a fine sterilized pipette, this process also serving to aërate the culture. A drop of the mixture was then placed upon the hœmacytometer, and the number of diatom cells per unit of volume, $0 \cdot 1$ cubic millimetre, was then 
found by counting. For each reading an average of four counts was made, a difference of ten diatoms being allowed for any accepted count.

Examination of the tables of results as a whole, will show that it would have been better to have used larger initial number of diatom cells since their minute size renders them very difficult to count when present in small numbers. This explains the irregularities in the early counts for the cultures of each series.

The sub-cultures were covered with the selected filters and then placed side by side in the window of a north room. The distance between the two end cultures was 80 centimetres. Opposite the window and $4 \cdot 2$ metres away from it, is a high grey wall of limestone, which receives direct sunshine only for a short time as the sun sets.

On 27.2.30, simultaneous measurements were made of the illumination of the window in the north room $\left(V_{s}\right)$ and of a perfectly open site on the laboratory roof $\left(V_{o}\right)$ by means of photometers furnished with vacuum photo-electric cells. (For method see Atkins and Poole, 1929.) It has been shown that on a dull day, the illumination at a point inside a building bears a very nearly constant ratio to the illumination at a point outside, and this ratio, expressed as a percentage, has been termed the daylight factor $\delta$. Table I shows these values over a period of half an hour.

\section{TABLE I.}

February 27, 1930. Grey sky, completely overcast, wind N.E. 12.1412.43 p.m. G.M.T.

Indoor site is the window-sill of a north room, where the photometer is moved over a range of $80 \mathrm{~cm}$. The outdoor site is a fixed position on a parapet of the Laboratory roof.

Indoor sites (in window sill).

Site 1.

Right extremity
occupied by
cultures.

Site 2.

To right of centre.

\begin{tabular}{cccc}
\multicolumn{2}{c}{$\begin{array}{c}\text { Illumination in } \\
\text { meter candles. }\end{array}$} & \multicolumn{2}{c}{ Daylight } \\
Factor. \\
$\begin{array}{c}\text { In open } \\
\text { on Roof }\end{array}$ & $\begin{array}{c}\text { window } \\
\text { sill }\end{array}$ & Vs. & \\
Vo. & Vs. & $\overline{\text { Vo }}=\delta$ & $\begin{array}{c}\text { Average } \\
\delta\end{array}$ \\
12,000 & 1,950 & $16 \cdot 2$ & \\
10,200 & 1,490 & $14 \cdot 6$ \\
9,150 & 1,389 & $15 \cdot 2$ \\
8,500 & 1,392 & $16 \cdot 4$
\end{tabular}

$15 \cdot 6$

1. $12 \cdot 19 \quad 10,500 \quad 1,930 \quad 18 \cdot 5$

2. $\begin{array}{llll}12 \cdot 20 & 12,200 & 2,360 & 19 \cdot 3\end{array}$

$\begin{array}{lllll}3 . & 12 \cdot 21 & 13,600 & 2,340 & 17 \cdot 2\end{array}$

4. $\begin{array}{llll}12 \cdot 22 & 13,800 & 2,520 & 18 \cdot 3\end{array}$ 
Indoor sites
(in window sill).

Site 3.

Centre of window.

Site 5.

Extreme left of centre.

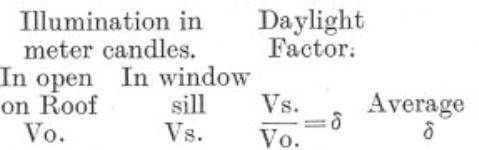

1. $\begin{array}{llll}12 \cdot 23 & 12,200 & 2,520 & 20 \cdot 7\end{array}$

2. $12 \cdot 24 \quad 15,200 \quad 2,680 \quad 17 \cdot 6$

3. $\begin{array}{llll}12 \cdot 25 & 14,100 & 2,290 & 16 \cdot 2\end{array}$

4. $\begin{array}{llll}12 \cdot 26 & 13,000 & 2,680 & 20 \cdot 6\end{array}$

5. $\begin{array}{llll}12 \cdot 27 & 13,200 & 2,560 & 19 \cdot 7\end{array}$

6. $12 \cdot 28 \quad 11,800 \quad 1,880 \quad 15 \cdot 9$

$18 \cdot 45$

$\begin{array}{crrrrr}\text { Site } 4 . & 1 . & 12 \cdot 29 & 11,100 & 1,610 & 14 \cdot 5 \\ \text { To left of centre. } & 2 . & 12 \cdot 30 & 9,690 & 1,410 & 14 \cdot 7 \\ & 3 . & 12 \cdot 31 & 10,900 & 2,110 & 19 \cdot 3 \\ & 4 . & 12 \cdot 32 & 12,400 & 2,170 & 17 \cdot 5 \\ & 5 . & 12 \cdot 33 & 15,400 & 2,660 & 17 \cdot 4 \\ & 6 . & 12 \cdot 34 & 14,200 & 2,310 & 16 \cdot 3\end{array}$

$16 \cdot 6$

1. $\begin{array}{llll}12 \cdot 35 & 13,600 & 2,060 & 15 \cdot 2\end{array}$

2. $12 \cdot 36 \quad 14,800 \quad 2,260 \quad 15 \cdot 3$

3. $\begin{array}{rlll}12 \cdot 37 & 15,600 & 2,660 & 17 \cdot 1\end{array}$

4. $12 \cdot 38 \quad 13,300 \quad 2,000 \quad 15 \cdot 1$

5. $12 \cdot 39 \quad 11,400 \quad 1,610 \quad 14 \cdot 2$

6. $12 \cdot 40 \quad 11,300 \quad 1,550 \quad 13 \cdot 8$

7. $12 \cdot 41 \quad 14,900 \quad 2,310 \quad 15 \cdot 6$

8. $12 \cdot 42 \quad 12,400 \quad 1,670 \quad 13 \cdot 5$

9. $12 \cdot 44 \quad 10,800 \quad 1,680 \quad 15 \cdot 6$

$15 \cdot 6$

Total average for the four sites is $16 \cdot 6$ for $\delta$.

\section{The Filters used.}

The filters selected were twelve in number, and Table II gives the details concerning their transmissions of energy and wave length. The non-selective screens were Wratten filters of certain known reduced intensities. The transmissions ( $\mathrm{T}$ ) for these were :- $\mathrm{T}=50 \%, 25 \%$, $12.5 \%, 6 \cdot 25 \%$ and $3 \cdot 1 \%$ respectively, but unhappily the gelatine films were damaged at the outset of the experiments, and their actual transmissions determined photo-electrically, using a sodium vacuum sensitive cell, were $\mathrm{T}=41 \cdot 8 \%, 19 \cdot 2 \%, 9 \cdot 24 \%, 3 \cdot 26 \%$ and $1 \cdot 66 \%$ respectively.

For convenience these filters will be referred to as Wratten filters $\mathrm{T}=\frac{1}{2}, \mathrm{~T}=\frac{1}{4}, \mathrm{~T}=\frac{1}{8}, \mathrm{~T}=\frac{1}{18}$ and $\mathrm{T}=\frac{1}{32}$ respectively. The makers' figures refer, however, to light incident normally whereas the photo-electric 
measurements refer to light received from the sky as a whole. The latter are necessarily lower than the former on account of the oblique incidence.

Six selective filters were used. Four were of Corning glass of red, orange, green and blue shades, and the actual percentage transmissions for these were determined by Dr. H. H. Poole (Dublin) by means of a Moll thermopile. Figure 2 shows the curves obtained from his data together with the transmission curves of the other coloured filters used.

\section{TABLE II.}

To SHOW THE WAVE LENGTHS, LIGHT TRANSMISSIONS AND RELATIVE ENERGY VALUES FOR THE SCREENS AND FILTERS USED FOR THE CULTURE EXPERIMENTS.

\begin{tabular}{|c|c|c|c|c|c|}
\hline $\begin{array}{l}\text { Screen or } \\
\text { filter used. }\end{array}$ & $\begin{array}{l}\text { Thick- } \\
\text { ness of } \\
\text { screen } \\
\text { used. } \\
\text { mm. }\end{array}$ & $\begin{array}{l}\text { Wave } \\
\text { length } \\
\text { in } \mathrm{m} \mu \text {. }\end{array}$ & $\begin{array}{c}\text { Actual } \\
\text { percentage } \\
\text { light } \\
\text { transmitted } \\
\text { T. }\end{array}$ & $\begin{array}{l}\text { Average } \\
\text { relative } \\
\text { energy in } \\
\text { arbitrary } \\
\text { units (from } \\
\text { Dr. Abbot's } \\
\text { data). }\end{array}$ & $\begin{array}{l}\text { Total } \\
\text { percentage } \\
\text { relative } \\
\text { energy } \\
\text { transmitted } \\
\text { E. }\end{array}$ \\
\hline Solar spectrum & & & 100 & 2,880 & 100 \\
\hline Wratten neutral & & & & & \\
\hline 1. Wratten $\mathrm{T}=\frac{1}{2}$ & & $400-720$ & $41 \cdot 8$ & 1,240 & $41 \cdot 8$ \\
\hline 2. $\quad, \quad \mathrm{T}=\frac{1}{4}$ & & , & $19 \cdot 2$ & 570 & $19 \cdot 2$ \\
\hline,$\quad \mathrm{T}=\frac{1}{8}$ & & , & $9 \cdot 5$ & 274 & $9 \cdot 5$ \\
\hline $\mathrm{T}=\frac{}{16}$ & &, & $3 \cdot 3$ & 95 & $3 \cdot 3$ \\
\hline 5. $\quad, \quad \mathrm{T}=\frac{1}{32}$ & & , & $1 \cdot 7$ & 49 & $1 \cdot 7$ \\
\hline 6. Ordinary glass & & & $71 \cdot 0$ & 2,040 & $71 \cdot 0$ \\
\hline 7. Corning red & 2.96 & $620-720$ & $67 \cdot 1$ & 602 & $20 \cdot 9$ \\
\hline 8.,$\quad$ orange & $2 \cdot 96$ & $570-720$ & $73 \cdot 0$ & 990 & $34 \cdot 5$ \\
\hline green & $3 \cdot 47$ & $490-570$ & $13 \cdot 4$ & 96 & $3 \cdot 3$ \\
\hline 10. ,, blue & $2 \cdot 96$ & $400-490$ & $60 \cdot 4$ & 490 & $17 \cdot 0$ \\
\hline 11. Schott and Gen blue & $2 \cdot 21$ & $400-490$ & $50 \cdot 3$ & 406 & $14 \cdot 0$ \\
\hline 12. Chance blue & & $400-490$ & $36 \cdot 2$ & 293 & $10 \cdot 2$ \\
\hline 13. Heat absorbing screen & & $400-720$ & $27 \cdot 7$ & 795 & $27 \cdot 7$ \\
\hline $\begin{array}{l}\text { 14. Heat absorbing }+ \\
\text { Corning blue }\end{array}$ & & $400-490$ & $16 \cdot 7$ & 135 & $4 \cdot 7$ \\
\hline
\end{tabular}

One of these was a blue glass prepared by Schott and Gen of Germany, and the transmission curve was obtained from data supplied by them. The other blue filter was prepared by Chance of Birmingham and the curve for it was obtained by resolving values read from a photograph of the density curve supplied by them. (Density $=\log \frac{1}{\text { transmission }}$ ). It may be observed from Figure 2, that the Corning blue transmits a certain low percentage of parasitic red rays. These were eliminated in some experiments, by placing a heat absorbing screen of a green shade over the Corning blue, which effectively cuts off these red rays, but lowers the intensity considerably. A suitable correction has been applied for this, in interpreting the results with the combination of screens. The 
other blue screens furnish a blue light of a high degree of purity, the Chance blue shows no inclusion of red at all.

Lastly, a filter of ordinary glass was used as a control, and since it was of a greenish tinge the amount of blue light passing through was lowered, and the total intensity of the light received reduced.

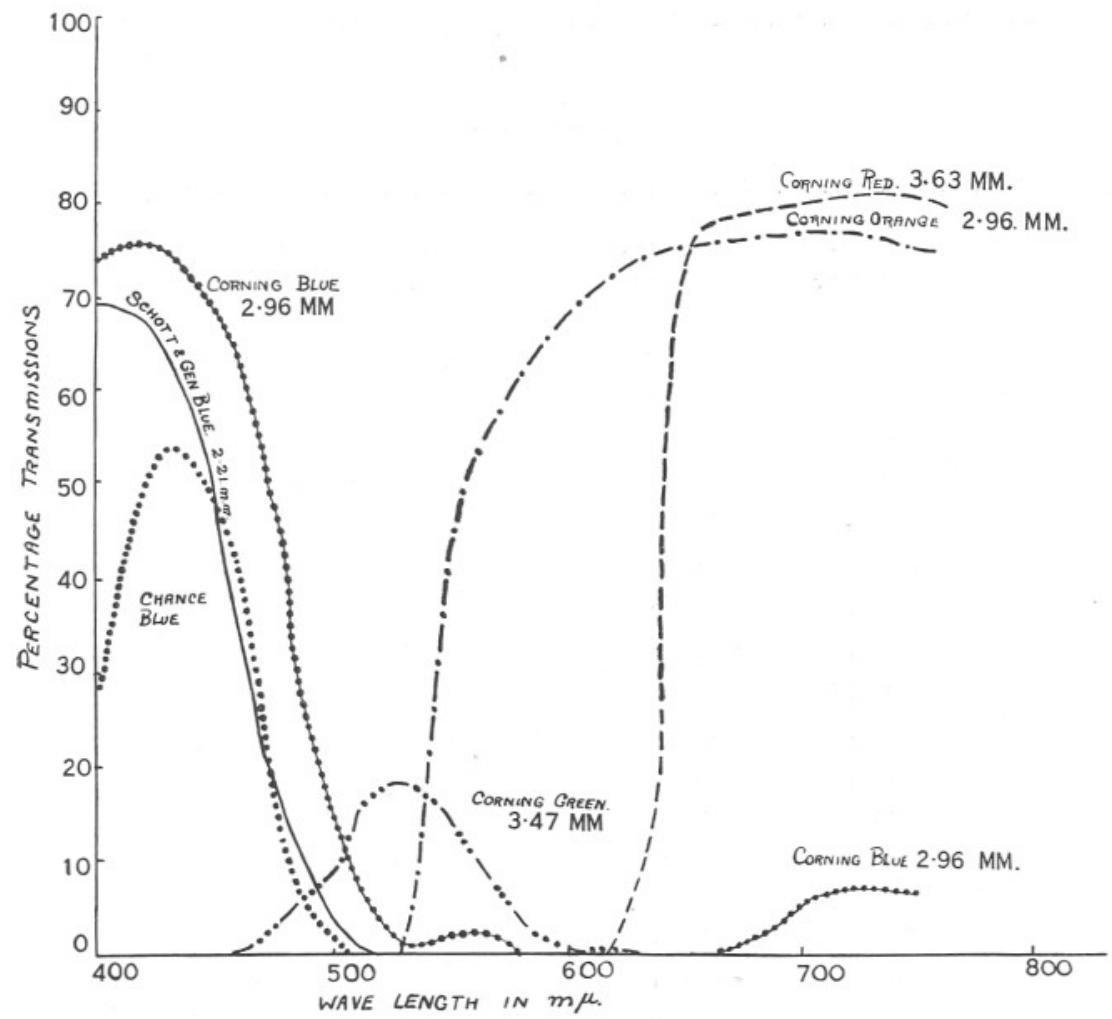

FIg. 2.-The ordinates are percentage transmissions for the selective screens used as determined, using a Moll thermopile. The abscissæ are wave length in $\mathrm{m} \mu$. The curves for the Chance blue, Schott and Gen blue glasses were obtained from data supplied by those firms as corrected for reflection losses for light incident normally.

\section{The Relative Energy of the Filters Used.}

Owing to lack of apparatus it was impossible to determine the relative energy transmitted through the screens directly, but it is hoped that this will be done shortly. The energy value is one which is undergoing constant change throughout the day, since it varies considerably in the different portions of the spectrum, and the proportion of the red, yellow, green and blue light changes from hour to hour according to the time of day and the condition of the sky light. An attempt to obtain approximate 
values of the relative energy in arbitrary units was made in the following manner.

At the Seventh International Congress of Photography, 1929, it was recommended that the following energy values derived from data of Dr. C. G. Abbot (Smithsonian Institute, U.S.A.) should be adopted as defining the spectral composition of mean noon sunlight. Table III shows these values for the visible part of the spectrum.

\section{TABLE III.}

Relative energy values from data of Dr. C. G. Abbot.

$\begin{array}{cccc}\begin{array}{c}\text { Wave } \\ \text { Length. }\end{array} & \begin{array}{c}\text { Relative } \\ \text { Energy. }\end{array} & \begin{array}{c}\text { Wave } \\ \text { Length. }\end{array} & \begin{array}{c}\text { Relative } \\ \text { Energy. }\end{array} \\ 360 & 16 \cdot 0 & 550 & 101 \cdot 7 \\ 370 & 20 \cdot 5 & 560 & 100 \cdot 0 \\ 380 & 25 \cdot 1 & 570 & 98 \cdot 4 \\ 390 & 30 \cdot 1 & 580 & 97 \cdot 2 \\ 400 & 45 \cdot 2 & 590 & 95 \cdot 6 \\ 410 & 57 \cdot 2 & 600 & 95 \cdot 2 \\ 420 & 65 \cdot 8 & 610 & 94 \cdot 3 \\ 430 & 69 \cdot 2 & 620 & 93 \cdot 2 \\ 440 & 77 \cdot 2 & 630 & 92 \cdot 2 \\ 450 & 86 \cdot 8 & 640 & 91 \cdot 0 \\ 460 & 92 \cdot 2 & 650 & 89 \cdot 7 \\ 470 & 96 \cdot 9 & 660 & 88 \cdot 5 \\ 480 & 99 \cdot 0 & 670 & 86 \cdot 4 \\ 490 & 100 \cdot 6 & 680 & 84 \cdot 7 \\ 500 & 101 \cdot 8 & 690 & 82 \cdot 7 \\ 510 & 101 \cdot 2 & 700 & 80 \cdot 5 \\ 520 & 101 \cdot 2 & 710 & 78 \cdot 1 \\ 530 & 101 \cdot 1 & 720 & 76 \cdot 1 \\ 540 & 100 \cdot 9 & & \end{array}$

Using these figures it was calculated that the average value for the relative energy transmitted from $720 \mathrm{~m} \mu-400 \mathrm{~m} \mu$. was 89.9 units per sq. cm. per minute, and the light transmitted over this region was taken as $100 \%$. The total energy transmitted, $\mathrm{E}$, for the visible spectrum was thus proportional to $89 \cdot 9 \times(720-400)=2880$ arbitrary units. Since this is the maximum value for $\mathrm{E}$, it may be taken as 100 , and the values of $\mathrm{E}$ for the light filters then found by substitution, e.g. considering the Corning red filter $\frac{89 \cdot 9 \times(72-62)}{2880}=31 \cdot 2 \%$, and this is the proportion of 
red as defined in the spectral curve. Of this the filter transmits $67 \cdot 1 \%$, so that the total relative energy transmitted is only $21.0 \%$. Column 5 , Table II, shows the values of $\mathrm{E}$ for all the filters used.

\section{RESULTS OF OBSERVATIONS}

Attempts were first made to conduct the experiments in the open, but the temperature was too high for the growth of the diatoms, and the light intensity also, for all but the more heavily screened.

Three series of observations were made indoors :- a preliminary series in May, 1929, followed by a second series June 13th-July 28th, 1929, which is referred to as the "summer" series. In both cases filters 1-10, Table II, were used. During the interval between the second and third series (January-March, 1930), the actual transmissions of the filters had been determined by Dr. H. H. Poole, revealing the presence of parasitic red rays in the Corning blue. In the third set of observations, therefore, precautions were taken to exclude the red rays of the blue filter by placing a heat-absorbing screen over it, as previously described. The light intensity $\mathrm{T}$ was then reduced to $15 \cdot 0$ and the relative energy $\mathrm{E}$ to $4 \cdot 7 \%$. The Schott and Gen and Chance blue filters were used in January in addition to the other filters.

\section{Preliminary Series, May 6th-28th, 1929.}

Average hours of sunshine 9 hours daily.

Tables IV, V, and VI are the results of observations made upon the rate of growth of the marine diatom Nitzschia closterium, when grown in "Miquel sea-water," under selective or non-selective screens as described in the preceding pages. The following list of screens used indicates the order of the cultures in the window, starting from the right-hand side :-

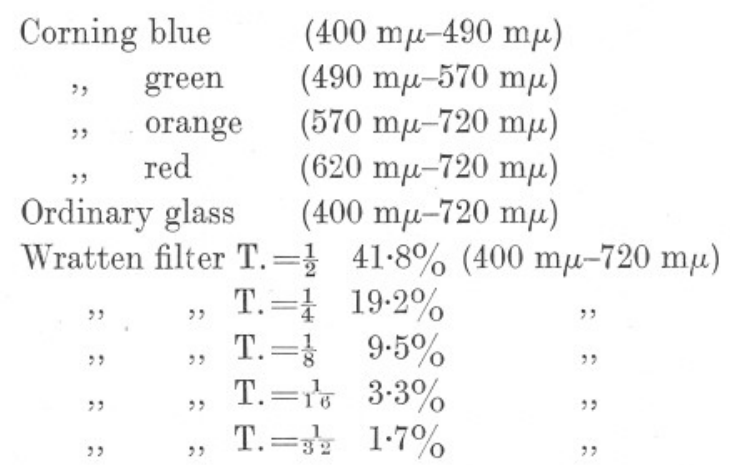




\section{TABLE IV}

Sub-cultures of Nitzschia closterium Grown IN Crucibles under Ordinary Glass, from 6TH-28TH May, 1929.

$\begin{array}{ccc}\text { Date. } & \text { No. of days. } & \begin{array}{c}\text { No. of diatoms per } \\ \text { unit of volume. }\end{array} \\ 9.5 .29 & 3 & 18 \\ 13.5 .29 & 7 & 85 \\ 16.5 .29 & 10 & 123 \\ 21.5 .29 & 15 & 270 \\ 23.5 .29 & 17 & 432 \\ 28.5 .29 & 22 & 546\end{array}$

\section{TABLE V.}

Sub-cultures of Nitzschia closterium Grown IN Crucibles under Neutral Wratten Filters from 9th-28th May, 1929.

$\begin{array}{cccccrr}\text { Date. } & \begin{array}{c}\text { No. of } \\ \text { days. }\end{array} & \mathrm{T}=\frac{1}{32} & \begin{array}{c}\text { No. of diatoms per unit of volume. } \\ \mathrm{T}=\frac{1}{10}\end{array} & \mathrm{~T}=\frac{1}{8} & \mathrm{~T}=\frac{1}{4} & \mathrm{~T}=\frac{1}{2} \\ 13.5 .29 & 4 & & & & & \\ 16.5 .29 & 7 & 6 & 1 & 42 & 13 & 32 \\ 21.5 .29 & 12 & 6 & 3 & 60 & 315 & 340 \\ 23.5 .29 & 14 & 14 & 18 & 218 & 475 & 485 \\ 28.5 .29 & 19 & 30 & 42 & 590 & 1400 & 1206\end{array}$

TABLE VI.

Sub-cultures of Nitzschia closterium Grown in Crucibles under Selective Filters of Corning Glass from 13Th-23Rd May, 1929.

\begin{tabular}{ccrrrr} 
& & \multicolumn{5}{c}{ No. of diatoms per unit of volume. } \\
Date. & No. of days. & Red. & Orange. & Green. & Blue. \\
16.5.29 & 3 & 2 & 3 & 0 & 2 \\
21.5 .29 & 8 & 120 & 69 & 152 & 56 \\
23.5 .29 & 10 & 285 & 241 & 270 & 106
\end{tabular}

The figures in the tables represent the number of diatoms per unit of volume $\left(0 \cdot 1 \mathrm{~mm}^{3}\right)$ as counted with the aid of a hæmacytometer. From these results it would appear during the period of observation for May 1929 :-

1. That the diatoms can utilise light of all wave lengths.

2. That light of reduced intensities is much more favourable than full illumination at this time of year. Light reduced to about $6 \%-3 \cdot 3 \%$ being the most suitable of the series. 
Second Series, June 13th-July 29th, 1929.

Table VII gives the results of observations from a new series of subcultures grown under the same conditions as in the preliminary experiments and occupying the same sites as formerly. During this period,

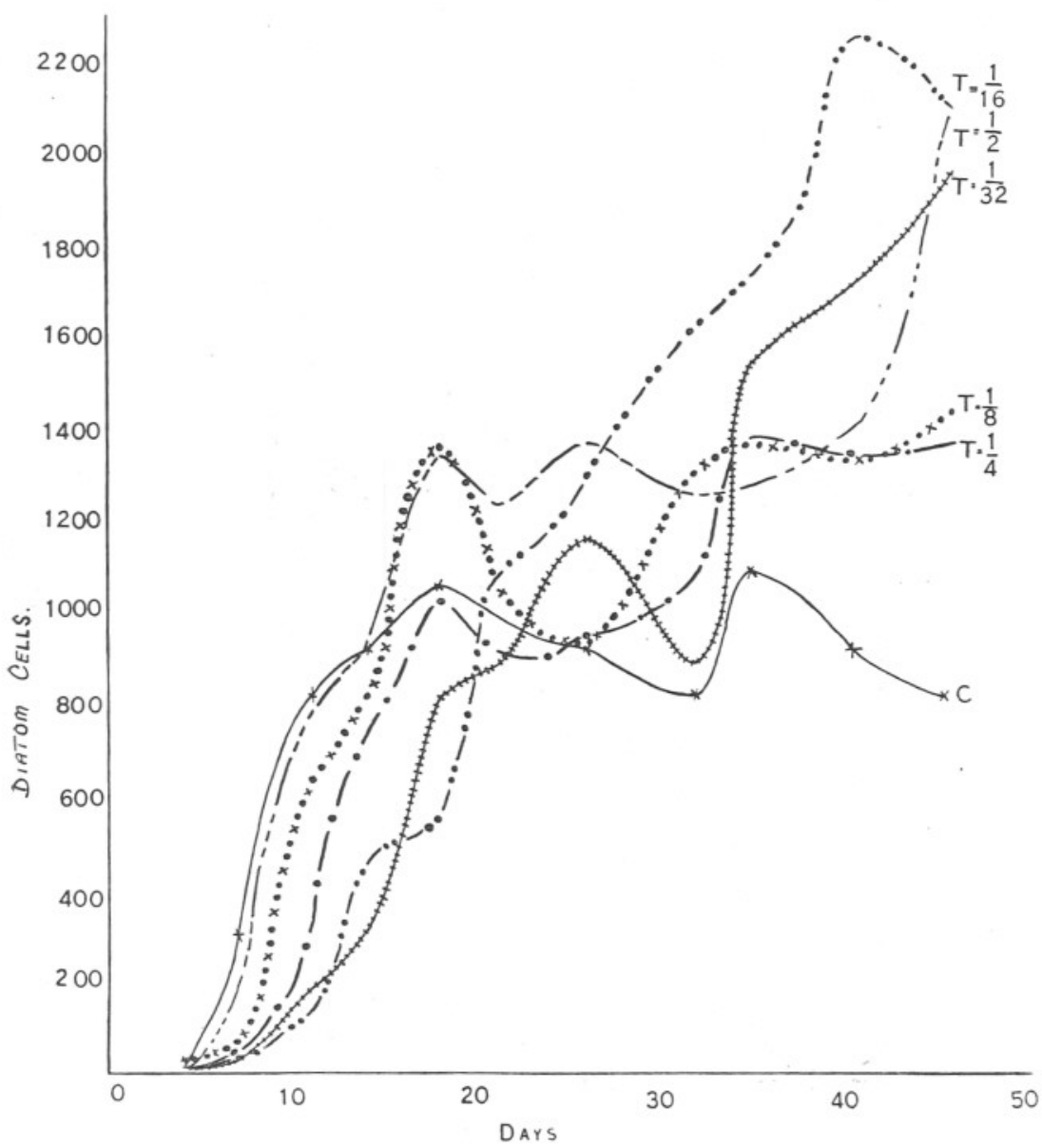

FIG. 3.-The ordinates are numbers of diatom cells in $0 \cdot 1$ cubic millimetre. The abscissæ are days. The curves show the rates of growth of the cultures of Nitzschia closterium, when grown under screens reducing the light intensity non-selectively, for a period of 46 days during the months of June and July, 1929.

however, the average number of hours of sunshine was 8 hours 11 minutes for June and 8 hours 49 minutes for July. Many days had 14 hours sunlight. Figures 3 and 4 give the curves obtained from the data.

When grown in ordinary flasks, cultures of Nitzschia closterium appear yellowish brown. Distinct colour changes of the cultures grown under 
the selective filters were observed during this second series, and also throughout the January-March growths. Under the heading of the concluding remarks for the last series, the subject is dealt with more fully. Reference to Figure 6 will show at a glance that a curious drop in the

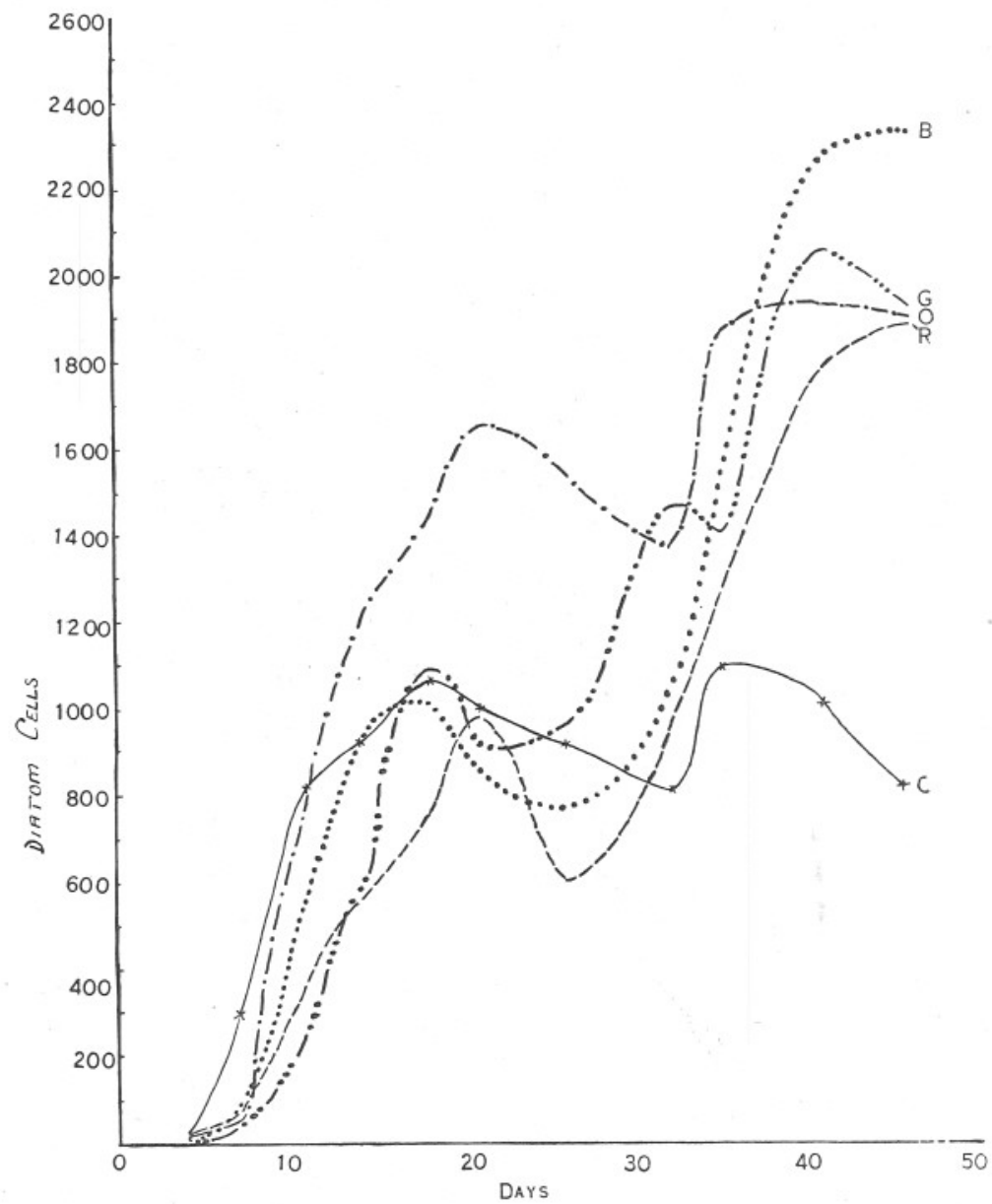

Fig. 4.-The ordinates are numbers of diatom cells in 0.1 cubic millimetre. The abscisse are days. The curves show the rates of growth of the cultures of Nitzschia closterium, when grown under screens reducing the light selectively, for a period of 46 intensity days during June and July, 1929.

number of diatoms is shown by all the growths. Allen and Nelson (1910) state that the siliceous shell of marine diatoms generally, is markedly thinner than in the great majority of other forms, and that this is even more emphasised in cultural forms. Dr. Allen has also stated that it is a common experience for cultures to show periodic decrease in numbers. 


\section{TABLE VII.}

To Show the Growth of the sub-cultures of Nitzschia closterium Grown under Selective ANd NonSElective Filters, from June 13Th-July 29TH, 1929.

\begin{tabular}{|c|c|c|c|c|c|c|c|c|c|c|c|c|}
\hline & & & & & & & No. of dia & $\begin{array}{l}\text { s per unit } \\
\text { Ordinary }\end{array}$ & volume. & & & \\
\hline No. & days. & & $\mathrm{T}=\frac{1}{32}$ & $\mathrm{~T}=\frac{1}{10}$ & $\begin{array}{c}\text { Wratten nilters. } \\
\qquad \mathrm{T}=\frac{1}{8}\end{array}$ & $\mathrm{~T}=\frac{1}{4}$ & $\mathrm{~T}=\frac{1}{2}$ & Glass. & Red. & Yellow. & Green. & Blue. \\
\hline 4 & . & . & 4 & 4 & 24 & 8 & 2 & 15 & 19 & 20 & 9 & 8 \\
\hline 7 & . & . & 22 & 36 & 64 & 147 & 196 & 299 & 68 & 54 & 51 & 92 \\
\hline 11 & . & . & 184 & 132 & 620 & 336 & 792 & 816 & 384 & 786 & 276 & 576 \\
\hline 14 & . & . & 304 & 468 & 816 & 732 & 924 & 920 & 552 & 1184 & 584 & 920 \\
\hline 18 & . & * & 812 & 544 & 1360 & 1024 & 1344 & 1060 & 728 & 1444 & 1092 & 1016 \\
\hline 21 & . & & 884 & 1072 & 1060 & 912 & 1234 & 996 & 976 & 1652 & 920 & 860 \\
\hline 26 & . & & 1160 & 1296 & 932 & 940 & 1372 & 920 & 604 & 1548 & 968 & 772 \\
\hline 32 & . & & 886 & 1624 & 1304 & 1088 & 1256 & 816 & 980 & 1372 & 1468 & 1060 \\
\hline 35 & . & & 1544 & 1860 & 1368 & 1376 & 1720 & 1092 & 1276 & 1864 & 1404 & 1540 \\
\hline 41 & . & & 1728 & 2256 & 1330 & 1340 & 1412 & 1012 & 1788 & 1928 & 2064 & 2272 \\
\hline 46 & . & • & 1868 & 2092 & 1432 & 1336 & 2080 & 812 & 1884 & 1900 & 1920 & 2328 \\
\hline
\end{tabular}


Accordingly, a special watch was made for empty frustules, and these were very seldom seen. The problem of the fate of the diatoms, which causes these well-marked falls in the curves, is further discussed in the third series. It may be mentioned here, however, that this decrease can hardly be due to lack of food material. Under the ordinary course of the experiments the volume of the culture solutions was made up to 10 c.c. from time to time by the addition of distilled water, to compensate for the small losses in volume due to evaporation and the minute drops extracted for counting purposes. After the 29th July, 1929, however, the observations were abandoned for about two months. During this time the cultures remained untouched. Yet counts made for all the cultures on September 29th, 1929, showed such dense growths that it was almost impossible to see the ruling on the hæmacytometer when drops were examined in the usual way after the culture solutions had been restored to their original volume of 10 c.c. with distilled water.

\section{Conclusions from Second Series.}

Thus it appears that diatoms can utilise light of all wave lengths even in the green region of the spectrum. It is true that the Corning green transmits parasitic rays of yellow and blue, but the percentage is so small as to be scarcely responsible for the astonishing growth under a screen which has a total transmission of light of only 13.5\%. Miquel (1892) found that orange light was best suited to the growth of freshwater diatoms. A study of Table VII will show that orange light is highly favourable for growth of the marine diatom Nitzschia, being slightly better than red, which it includes. During the last few days of the experiments the numbers under the blue and green filters exceeded those of the diatoms under both the red and orange. It must be remembered that the Corning blue filter was transmitting a small percentage of parasitic red rays, but results obtained in the third series indicate that they alone are not responsible for the prolific growth under this screen.

The light intensity and energy transmitted by the control ( $\mathrm{T}$ and $\mathrm{E}$ $=71 \%$ ) were too high for good growth, the amounts transmitted by all the reducing non-selective filters being much more favourable. Under the selective filters the cultures grew well, for although the light intensity was in some cases high, e.g. orange and red, the relative energy in these regions is considerably less than for white light (Table II).

Third Series. Winter and Early Spring. January 2nd-April 14th, 1930.

The cultures were set up in the same manner as before, the only difference being in the use of additional filters, viz. the heat-absorbing 
screen which was placed over the Corning blue, and the extra filters of Schott blue, and Chance blue (Nos. 11, 12, and 13, Table II).

Attention is here drawn to the fact that the transmission curves for 11

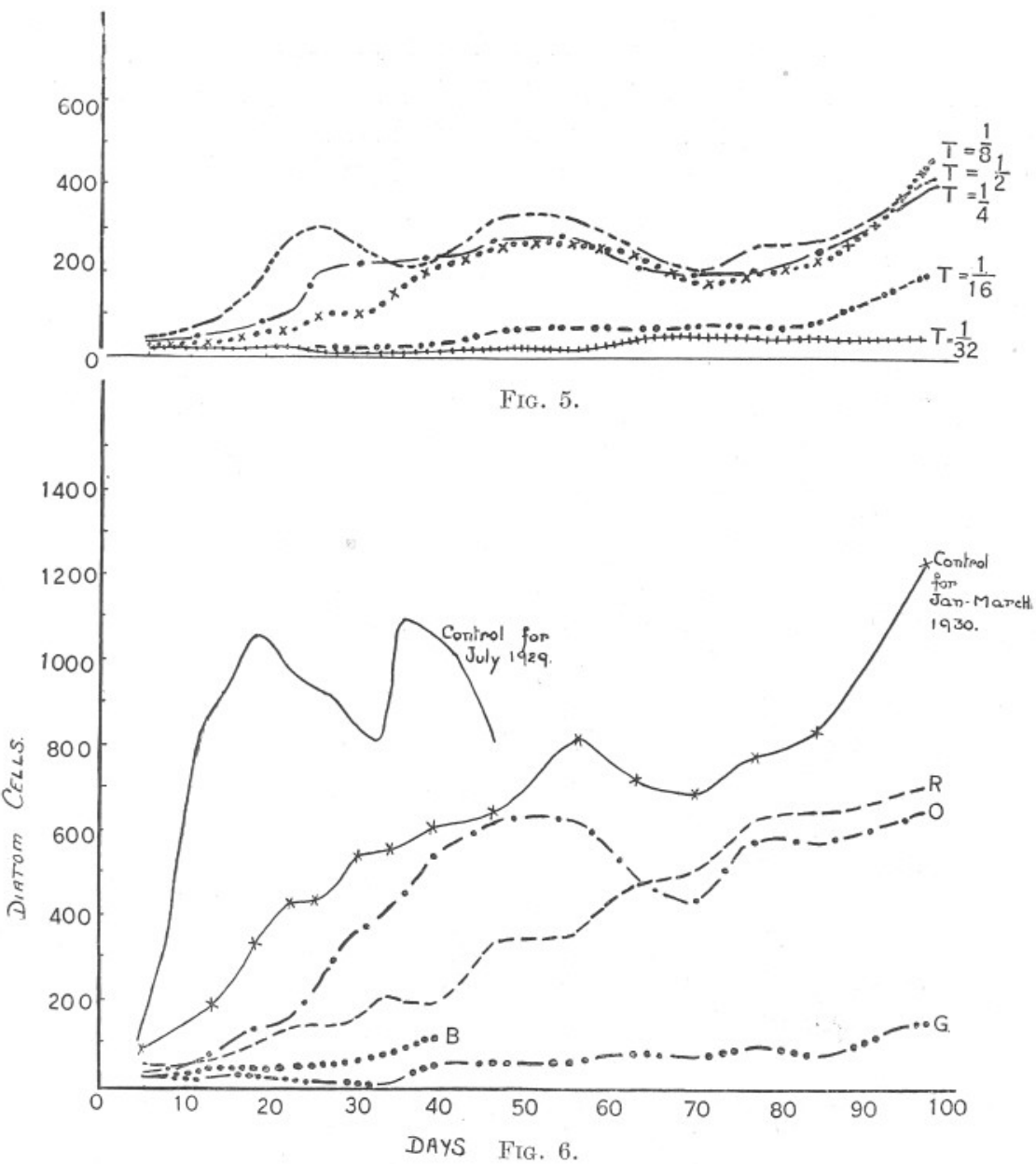

FIGs. $5 \& 6$. -The ordinates are numbers of diatom cells in $0 \cdot 1$ cubic millimetre. The abscissæ are days. The curves show the rates of growth of the cultures of Nitzschia closterium when grown under screens reducing the light intensity selectively, Fig. 6, lower portion, and non-selectively Fig. 5, upper portion, for a period of 97 days during January-March, 1930. The curve showing growth under the control screen during June and July, 1929, is also shown.

and 12 were obtained from data supplied by the makers in January, 1930, and it has not been possible as yet to verify these figures, but the absence of any appreciable amount of red has been verified by visual spectroscopic examination. 
The average number of hours daily sunshine in January was 1 hour 10 minutes, in February 3 hours 18 minutes, and in March 3 hours 50 minutes. Table VIII and Figures 5, 6, and 7 are records of growth for this period.

\section{Conclusions from Third Series.}

1. The results suggest that the total light intensity received is a factor of great importance. Excepting the Schott blue filter, the diatoms under the ordinary glass screen show the best growth, whilst the cultures under

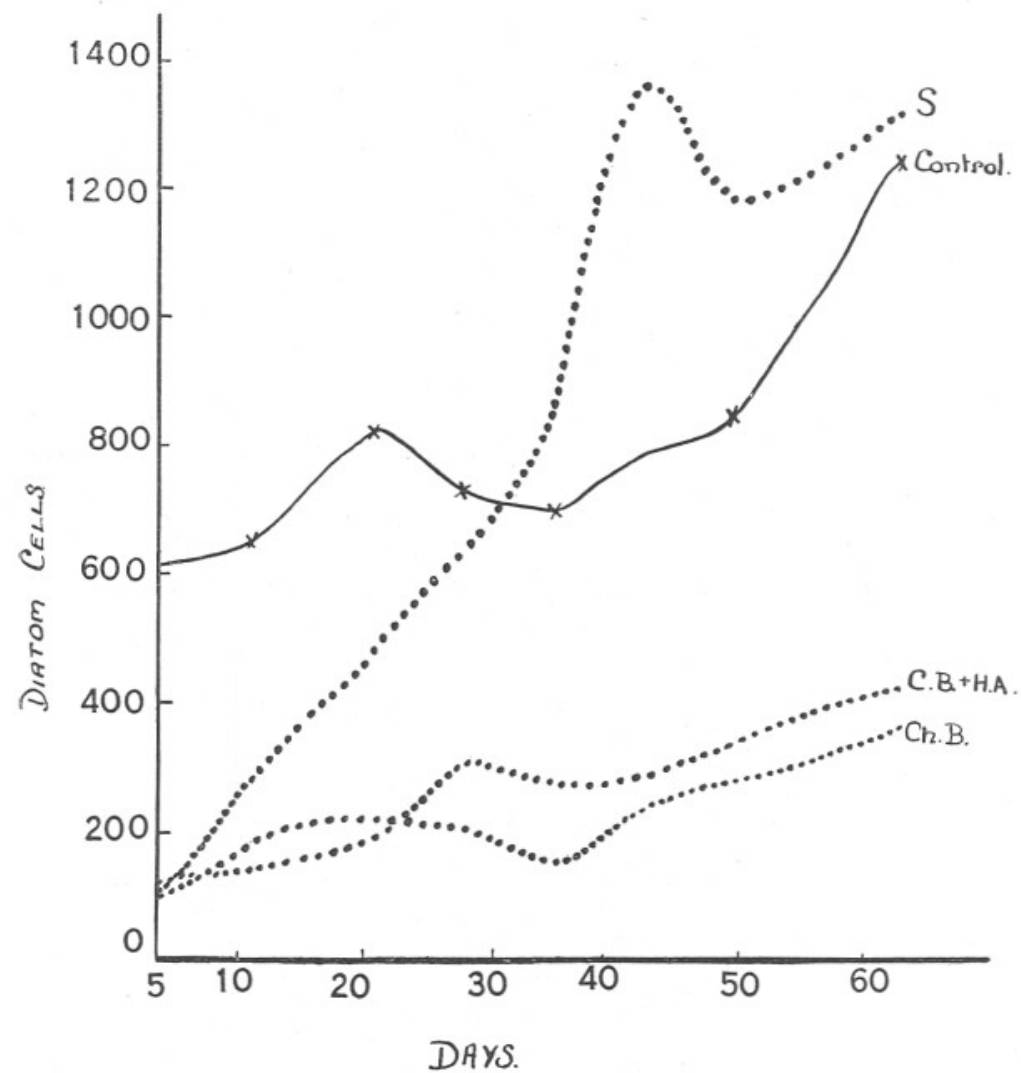

FIG. 7.-The ordinates are numbers of diatom cells in 0.1 cubic millimetre. The absciss $x$ are days. The curves show the rates of growth of the cultures of Nitzschia closterium when grown under the influence of blue light for a period of 63 days during February and March, 1930. The curve showing growth under the control screen during the same period is also given.

the Wratten filters show poor growth where the intensity is heavily reduced. The figures shown in Table IX would suggest that the relative energy is a limiting factor, the ratio $\frac{\text { Relative Energy }}{\text { No. of diatoms }}$ being a constant in the experiments and having a value of $24 \cdot 5$. 
To Show the Growth of the sub-Cultures of Nitzschia closterium Grown under Selective ANd Nonselective Filters from January 2ND-April 9th, 1930, and from February 5th-April 9th, 1930.

- 5

$$
\begin{array}{ll}
6 & 7
\end{array}
$$

$$
\begin{array}{lll}
8 & 9
\end{array}
$$$$
9
$$$$
10 \quad 1
$$$$
\text { Control Cor }
$$$$
\text { Corning Cornin }
$$

11

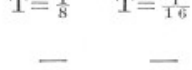

$\begin{array}{rrrr}\overline{28} & & & \\ 20 & 28 & 88 & 48 \\ 20 & 17 & 188 & 60 \\ 20 & 20 & 332 & 96 \\ 20 & 20 & 432 & 136 \\ 16 & 8 & 432 & 144 \\ 20 & 8 & 544 & 168 \\ 28 & 12 & 560 & 212 \\ 60 & 40 & 616 & 200 \\ 62 & 40 & 850 & 340 \\ 64 & 45 & 728 & 368 \\ 66 & 40 & 696 & 588 \\ 70 & 43 & 788 & 632 \\ 76 & 40 & 944 & 652 \\ 156 & 40 & 1244 & 716\end{array}$

$\begin{array}{rr}36 & -32 \\ 52 & 32 \\ 84 & 56 \\ 108 & 64 \\ 200 & 96 \\ 220 & 98 \\ 224 & 152 \\ 236 & 216 \\ 272 & 256 \\ 272 & 260 \\ 212 & 240 \\ 200 & 170 \\ 200 & 200 \\ 240 & 232 \\ 396 & 456\end{array}$

* Columns 13-16 give the figures for the cultures started February 4th, 1930.

$\begin{array}{rrrrrrr}\overline{48} & \overline{32} & \overline{20} & & & & \\ 72 & 20 & 45 & & & & \\ 136 & 26 & 40 & & & & \\ 160 & 16 & 44 & & & & \\ 224 & 9 & 50 & & & & \\ 368 & 8 & 60 & & & & \\ 428 & 8 & 88 & & & & \\ 544 & 57 & 116 & 116^{*} & 108^{*} & 104^{*} & 5 * \\ 624 & 60 & - & 140 & 281 & 184 & 12 \\ 630 & 60 & - & 192 & 484 & 216 & 22 \\ 500 & 88 & - & 302 & 640 & 200 & 29 \\ 436 & 82 & - & 276 & 860 & 150 & 36 \\ 576 & 100 & - & 280 & 1360 & 232 & 43 \\ 584 & 88 & - & 332 & 1180 & 280 & 50 \\ 656 & 168 & - & 420 & 1316 & 360 & 63\end{array}$




\section{TABLE IX}

To Show that the Ratio of the Relative Energy to the Number of Diatoms tends to be a Constant when the Relative Energy TRANSMITTED IS Low.

\begin{tabular}{|c|c|c|c|c|c|}
\hline \multicolumn{2}{|l|}{ Screen Used. } & $\mathrm{T}=\frac{1}{2 \pi}$ & $\mathrm{T}=\frac{1}{16}$ & $\begin{array}{l}\text { Corning } \\
\text { Green. }\end{array}$ & $T=\frac{1}{8}$ \\
\hline Percentage Light & Trans- & & & & \\
\hline mitted & . $\quad$. & $1 \cdot 7$ & $3 \cdot 3$ & $13 \cdot 5$ & $9 \cdot 5$ \\
\hline Percentage Relative & Energy & $1 \cdot 7$ & $3 \cdot 3$ & $3 \cdot 3$ & $9 \cdot 5$ \\
\hline No. of Diatoms at & the end & & & & \\
\hline of 84 days & . $\quad$. & 40 & 76 & 88 & 233 \\
\hline Relative Energy & & 23.5 & $23 \cdot 1$ & $26 \cdot 3$ & $25 \cdot 2$ \\
\hline$\overline{\text { No. of Diatoms }}$ & $\cdot$ & & 201 & & \\
\hline Average Ratio & . & $24 \cdot 5$ & & & \\
\hline
\end{tabular}

2. The large growth under the Schott blue filter $(T=50 \cdot 3$ and $\mathrm{E}=14 \cdot 0)$ is difficult to account for unless the screen transmits almost the optimum light intensity and energy. This view would explain the relatively poor growths under the Chance blue, and combined Corning and heat-absorbing screens where $\mathrm{T}=36$ and $\mathrm{E}=10$ for the Chance and $\mathrm{T}=16 \cdot 7$ and $\mathrm{E}=4 \cdot 7$ for the combination. Under the red filter $(\mathrm{T}=67, \mathrm{E}=30)$, and the orange ( $\mathrm{T}=73, \mathrm{E}=34$ ), the rates of growth were very similar to each other, that under the orange being slightly better than that under the red for the greater part of the third series. Unlike the summer results, the growths under these two filters were poorer than that under the ordinary glass screen. Under the green filter $(\mathrm{T}=13 \cdot 5, \mathrm{E}=3 \cdot 3)$ growth was poor, and suggested the importance of the relative energy transmitted when the light intensity was low (Table IX).

3 . The difference in colour exhibited by some of the cultures has already been referred to. When grown in ordinary culture flasks the growths are yellowish brown. Under the coloured screens they vary from a rich dark brown shade to decided greenish tints. Under the reduced light of the non-selective Wratten filters the cultures remained yellowish brown as under the control. These colours are not due to differences in the numbers of diatoms present, for counts made on April 9th gave 1244 per unit of volume under the glass filter and 1316 under the Schott blue, yet the culture under the latter was the rich brown colour, whilst under the ordinary glass the culture was yellowish brown. Under the red and yellow filters the cultures always assumed a decided yellow-green shade, whilst under the blue and green they were decidedly dark brown, i.e. the cultures tended to assume colours complementary to those in which they were grown. The dark brown colour of the cultures under the blue and 
green filters is probably an adaptation which helps to compensate the deficiency of red and yellow rays by furnishing an added power to absorb the rays available. This is of interest when it is considered that marine diatoms are frequently abundant between depths of 5-15 metres in the sea, being seldom found very near the surface because of the harmful effect of high light intensity. It is known that at a depth of 5 metres most. of the red rays are absorbed, whilst at 15 metres the light that penetrates is reduced to about $10-20 \%$ of the total intensity and is deprived of all the red, practically all the yellow, and consists of green and blue light only.

4. The cultures showed the same periodic decrease in numbers of diatoms similar to those of the summer series. Drops of solution from the cultures gave $\mathrm{pH}$ values from $\mathrm{pH} 8 \cdot 8-9 \cdot 2$, showing that the solutions in which the diatoms grew were strongly alkaline. Whilst silica is highly resistant to acids it yields to alkalines, and it is suggested that the falling off in numbers is due to the fact that the thin shells of the dead frustules are dissolved in the culture solutions. This view is upheld by the results of the following experiments. A certain volume of culture solution containing a known number of diatoms per $\mathrm{mm} .{ }^{3}$ was gently heated and kept just below boiling point for some time. The solution was then made up to the original volume with water and counts made for the number of individuals present in the usual way. Nearly all the diatoms had disappeared, suggesting that all but the most resistant frustules had dissolved, the boiling being a quick method of showing what would be a slow process in the culture solutions.

\section{GENERAL CONCLUSIONS.}

Three series of cultures of the marine diatom Nitzschia closterium were grown under selective and non-selective filters, the transmissions of which were known between definite limits of wave length.

From results of observations on the growth of the cultures it would appear :-

1. That the amount of energy transmitted is of greater importance than the precise wave lengths between which the energy so transmitted lies. When the amount of radiation is small then growth tends to be proportional to the relative energy, but when the energy received is too intense then the effect is harmful to the cultures.

2. At all times the cultures tend to show chromatic adaptation when grown under selective filters, assuming colours which are complementary to those in which they are growing, e.g. a dark rich brown shade under the green and blue screens and a decided green colour under the red and yellow. 
Since these experiments were completed, Klugh (1930) has published a further report on the effects of light of different wave lengths, but of equal intensities, on the photosynthetic rates for certain green and red algæ. His results would appear to confirm the conception of the complementary nature of the brown colour.

3. The cultures are subject to periodic decrease in numbers, which is probably due to the thin siliceous shells of the diatoms being dissolved in the culture solutions which have become highly alkaline.

\section{REFERENCES.}

Allen, E. J. 1914. On the culture of the Plankton Diatom Thallasiosira gravida Cleve, in Artificial Sea Water. Journ. Mar. Biol. Assoc., N.S., 10, Vol. X, pp. 417-439.

- 1919. A Contribution to the Quantitative Study of Plankton. Journ. Mar. Biol. Assoc., N.S., Vol. XII.

Allen, E. J., ANd Nelson, E. W. 1910. On the Artificial Culture of Marine Plankton Organisms. Quart. Journ. Micro. Sci., Vol. LV, Pt. 2, p. 373.

Atkins, W. R. G., ANd Poole, H. H. 1926. Photo-electric measurements of illumination in relation to plant distribution. Part 1, Sci. Proc. Royal Dublin Soc., Vol. XVIII, No. 25, pp. 277-298.

— 1929. 2. The photo-electric measurement of illumination in buildings. Loc. cit., Vol. XIX, No. 18, pp. 173-188.

Atkins, W. R. G. 1928. Seasonal Variations in the Phosphate and Silicate Content of Sea-water during 1926 and 1927 in Relation to the Phytoplankton Crop. Journ. Mar. Biol. Assoc., N.S., Vol. XV, No. 1, pp. 191-205.

Atkins, W. R. G., And Poole, H. H. 1929. Methods for the Photoelectric and Photo-chemical Measurement of Daylight. Conference of Empire Meteorologists, 1929. Agricultural Sections.

Blackman, F. F. 1904. Chromatic Adaptation. New Phytologist, Vol. III, pp. 237-242.

Dangeard, P. A. 1927. Recherches sur l'assimilation chlorophyllienne et les questions qui s'y rattachent le Botaniste. Le Botaniste, Series XIX.

Emerson, R. 1929. Chlorophyll Content and Rate of Photosynthesis. Proc. Nat. Acad. Sci., Vol. 15, No. 3, pp. 281-283.

- 1929. Photosynthesis as a function of Light Intensity and of Temperature with Different Concentrations of Chlorophyll. Journ. Gen. Physiol., Vol. XII, No. 5, pp. 623-639. 
Emerson, R. 1929. Relation Between Maximum Rate of Photesynthesis and Concentration of Chlorophyll. Loc. cit., Vol. XII, No. 5, pp. 609-622.

GAGE, H. P. 1924. Coloured Glass for Stage Illumination. Trans. Soc. Motion Picture Eng., U.S.A., May, 1924.

Hodgetss. 1922. A Study of some of the factors controlling the Periodicity of Freshwater Algæ in Nature. New Phytologist, Vol. XX, pp. 15-33.

KoDAK Co. 1925. Wratten Light Filters.

KLugh, Brooker A. 1925. Effect of Light of Different Wave Lengths on Rate of Reproduction of Volvox aurens and Closterium acerosum. New Phyt., Vol. XXIV, pp. 186-190.

- 1927. Light Penetration into the Bay of Fundy and into Lake Charncoot, New Brunswick. Ecology, Vol. 8, pp. 90-93.

- 1930. Studies on the Photosynthesis of Marine Algæ. No. 1. Photosynthetic Rates of Enteromorpha linza, Porphyra umbilicalis and Deleseria simuosa, in Red, Green and Blue Light. Cont. to Canadian Biology and Fisheries, Vol. II, No. 1, pp. 41-63.

Mann, A. 1921. Dependence of Fishes on Diatoms. Ecology, Vol. II, No. 2, pp. 79-83.

Marshall, S. M., and OrR, A. P. 1928. Photosynthesis of Diatom cultures in the Sea. Journ. Mar. Biol. Assoc., N.S., Vol. XV, No. 1, pp. 321-360.

Miquel. 1892. Recherches Experimentales sur la Physiologie, la Morphologie et la Pathologie Des Diatoms. Annals De Micrographie.

Poole, H. H., And Atkins, W. R. G. 1926. On the penetration of light into Sea-water. Journ. Mar. Biol. Assoc., N.S., Vol. XIV, No. 1, pp. 177-198.

1928. Further photo-electric measurements of the penetration of light into sea-water. Loc. cit., Vol. XV, No. 2, pp. 455-483.

— 1929. Photo-electric measurements of submarine illumination throughout the year. Loc. cit., Vol. XVI, pp. 297-324.

ShIrLey, H. 1929. The influence of Light Intensity and Light Quality upon the Growth of Plants. Amer. Journ. Bot., Vol. XVI, pp. 354390.

Stiles, W. 1925. Photosynthesis. London.

I am greatly indebted to Dr. E. J. Allen for laboratory facilities and to Dr. W.R. G. Atkins for suggesting the subject of the research and for his help and encouragement throughout the experiments. 
